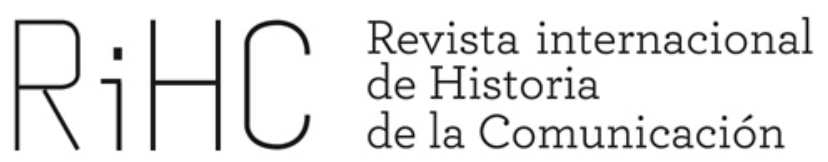

\title{
SOBREVUELO DE LA TELEGRAFÍA ÓPTICA EN LUSITANIA $^{1}$
}

DOI: http://dx.doi.org/10.12795/RiHC.2014.103.07

\author{
Gilles Mutigner \\ Universidad Complutense de Madrid \\ email@email.com (estilo RiHC_DatosAutor)
}

Resumen: La telegrafía óptica en Portugal, cuyos orígenes se sitúan en los albores del siglo XIX, es poco conocida, por no decir desconocida. En el transcurso del último decenio, diversos historiadores y aficionados de este país, y también del extranjero, civiles y militares, han estudiado este tema, con resultados, a veces imprecisos e incluso contradictorios, muy interesantes. En el presente trabajo me he propuesto hacer el balance de la cuestión y proporcionar una visión de conjunto, partiendo de las distintas obras publicadas, de los documentos extraídos de los archivos históricos, de contactos con especialistas y de búsquedas personales sobre el terreno. Visión de conjunto que integra las iniciativas que han conducido a la reconstrucción de algunas estaciones y que también atañe, aunque sólo sea tangencialmente, a la Extremadura española. No se trata, propiamente dicho, de una investigación, sino más bien de un artículo de divulgación que recoge, del conjunto de informaciones recogidas, los aspectos, tanto

\footnotetext{
1 Este estudio, en su versión francesa, fue objeto de exposición en las IV Journées d'Études (Télégraphie Chappe) de la Fédération Nationale des Associations de personnel de La Poste et de France Télécom pour la Recherche Historique (FNARH), celebradas en Épiniac (Francia), entre el 9 y el 11 de marzo de 2012.
} 
históricos como técnicos, más significativos, sin excluir por ello la incorporación de nuevos datos.

\begin{abstract}
The optical telegraphy in Portugal, whose origins are in the dawn of the nineteenth century, little is known, not to say unknown. In the course of the last ten years, various historians and amateurs of this country, and also from abroad, civil and military, have studied this subject, with results, at times vague and even contradictory, very interesting.

In the present work I have proposed to make an assessment of the issue and provide an overview, starting from the various published works, of the documents extracted from the historical archives, contacts with specialists and personal searches on the ground; overall vision that integrates the initiatives that have led to the reconstruction of some stations and that also applies, even if only tangentially, to the Spain's Estremadura.

It is not, itself, an investigation, but rather a disclosure paper that picks up, from the set of gathered information, the aspects, both historical and technical, more significant, without excluding the incorporation of new data.
\end{abstract}

Keywords: Telegraph, net, Wellington, Ciera, Folque

\title{
Introducción
}

La telegrafía óptica, "aérea" en Francia y "visual" en Portugal, también arranca, en este segundo país, hacia finales del siglo XVIII.

La primera línea de telegrafía visual (semafórica) portuguesa se extendía a lo largo del estuario del Tajo y de la costa atlántica, entre la ciudad de Lisboa y el Cabo da Roca [Fig. 1]. Según las fuentes en las que han buceado Isabel de Luna y Ana Catarina Sousa (2009: 75, n.22), el itinerario de la Linha da Barra o do Mar (cuyo nombre proviene de los bancos de arena en la desembocadura del río), partiendo de la ciudad, era el siguiente:

- $\quad$ 01.- Castel(I)o de S(ão) Jorge (antiguo Castelo dos Mouros)

- Freguesia do Castelo, Lisboa.

- 02.- en um dos guindastes da Ribeira $\left({ }^{*}\right)$ ou no Observatorio da Caza das Fornias (instalado en uno de los dos cabrestantes [del Astillero] de Ribeira [das Naus] [Hoy Praça do Comércio/Terreiro do Paço] o bien en el Observatorio de Caza das Fornias [?]. Observatorio y emplazamiento no localizados.

- Freguesia de Madalena/São Nicolau.

- 03.- no navio que serve de Cabria (en el navío que sirve de cabrestante) [?]. Ninguna referencia complementaria.

- 04.- Torre de Chagas [ ?] Torre no localizada.

- 05.- Forte de Alcântara [ ?] Fuerte no localizado. 
- Freguesia de Alcântara?

- 06.- na Cordoaria (en la Cordelería) o Cordoaria Nacional o Real Fábrica da Cordoaria da Junqueira o Real Cordoaria da Junqueira.

- Freguesia de Santa María de Belém.

- 07.- Torre de Belém (*)

- Freguesia de Santa María de Belém.

- 08.- Forte de (São Bruno de) Caxias (*)

- Freguesia de Caxias/ Concelho de Oeiras.

- 09.- Forte das Mai(y)as o Forte de São João das Maias o Forte de Oeiras

- Freguesia de Oeiras e São Julião da Barra/Concelho de Oeiras/Vila de Oeiras.

- 10.- Fortaleza (o Forte) de S(ão) Julião da Barra (*)

- Freguesia de Oeiras e São Julião da Barra/ Concelho de Oeiras/Vila de Oeiras.

- 11.- Forte de Santo Antônio (*) [da Barra] o Forte de Santo Antônio do Estoril o Forte Velho

- Freguesia de Estoril/Concelho de Cascais/Povoação de São João do Estoril.

- 12.- Fortaleza de Cascaes o Fortaleza/Forte de Nossa Senhora da Luz de Cascais (Cidadela) [Torre de Santo Antônio de Cascais o Torre Fortificada de Cascais o Torre de Cascais]

- Freguesia de Cascais/Concelho de Cascais/Vila de Cascais.

- 13.- Farol (Faro) da Guia (*)

- Freguesia de Cascais/ Concelho de Cascais/Vila de Cascais.

- 14.- Forte de Oitavos $\left({ }^{*}\right)$ o Forte de São Jorge de Oitavos

- Freguesia de Cascais/Concelho de Cascais.

- 15.- Forte das trez pedras [ ?] Sin huella del fuerte.

- 16.- Forte da Roca [ ?] Fuerte no localizado.

- 17.- Farol da Roca

- Freguesia de Colares/Concelho de Sintra.

$\left(^{*}\right)$ Puestos estratégicos también mencionados por Maria Fernanda Rollo (véase más abajo).

La mayoría de estas estaciones (18 según la fuente, pese a que sólo he logrado inventariar 17, a las que he añadido las distintas denominaciones atribuidas, así como su actual dependencia administrativa [freguesia/concelho, equivalentes a parroquia/municipio], si bien no he conseguido despejar las incógnitas que aún encierran algunos puntos estratégicos, señalados con [?]) estaban ubicadas en las fortalezas y faros que jalonan la costa. Estos puestos tenían por finalidad ejercer la vigilancia marítima y el control militar y aduanero del litoral, ${ }^{2}$ así como transmitir

2 Según Raeuber $(1993,96)$, “Conforme a las directrices, esta línea de comunicaciones estaba al servicio del almirantazgo portugués así como de las autoridades portuarias de Lisboa. Todos los navíos, tanto los buques de guerra como los mercantes, habían de ser señalados y debía especificarse la clase de 
mensajes por medio de banderas izadas en mástiles, como en los barcos. Un documento (Luna \& Sousa, 2008: 75) ${ }^{3}$, fechado en 1796, conservado en los Archivos de la Biblioteca Central de la Marina, en Lisboa, permite acreditar la existencia de un Reglamento (código) que comprendería 36 señales.

Según Maria Fernanda Rollo (2009 :37), entre las estaciones permanentes o utilizadas con más frecuencia figuran:

- 02.- Ribeira das Naus (Almirantado) [Astillero/Almirantazgo]

- nn.- Rocha do Pragal (Almada) [margen izquierda o Sur]

- Freguesia de Pragal/Concelho de Almada

- 07.- Torre de Belém

- 08.- Caxias

- 10.- Torre de San Julião

- 14.- Oitavos

- 11.- St. António

- nn.- [Vigia do] Facho o Vigia da Boca do Inferno

- $\quad$ Freguesia de Cascais/Concelho de Cascais

- 13.- Guia

Algunas de estas estaciones, tales como las de Rocha do Pragal y Facho, corresponden muy probablemente a la ampliación de la red desarrollada por Ciera unos años más tarde y que llegará hasta la margen izquierda del Tajo (Luna \& Sousa, 2008: 76; Rollo, 2009: 38). Habría que añadir entre los nuevos puestos de la Linha da Barra, los de Penedo y Buenos Aires, este último perteneciente a la freguesia de Lapa.

embarcación, su nacionalidad, si entraba o salía del Tajo, si se acercaba o acababa de pasar la barra, o si permanecía fondeada, y demás".

3 Signaes que a Rainha Nossa Senhora manda estabelecer e executar nas fortalezas e lugares nomeados (PT BCM - RDd4-31). 


\section{Fig 1. De Lisboa al Cabo de Roca}

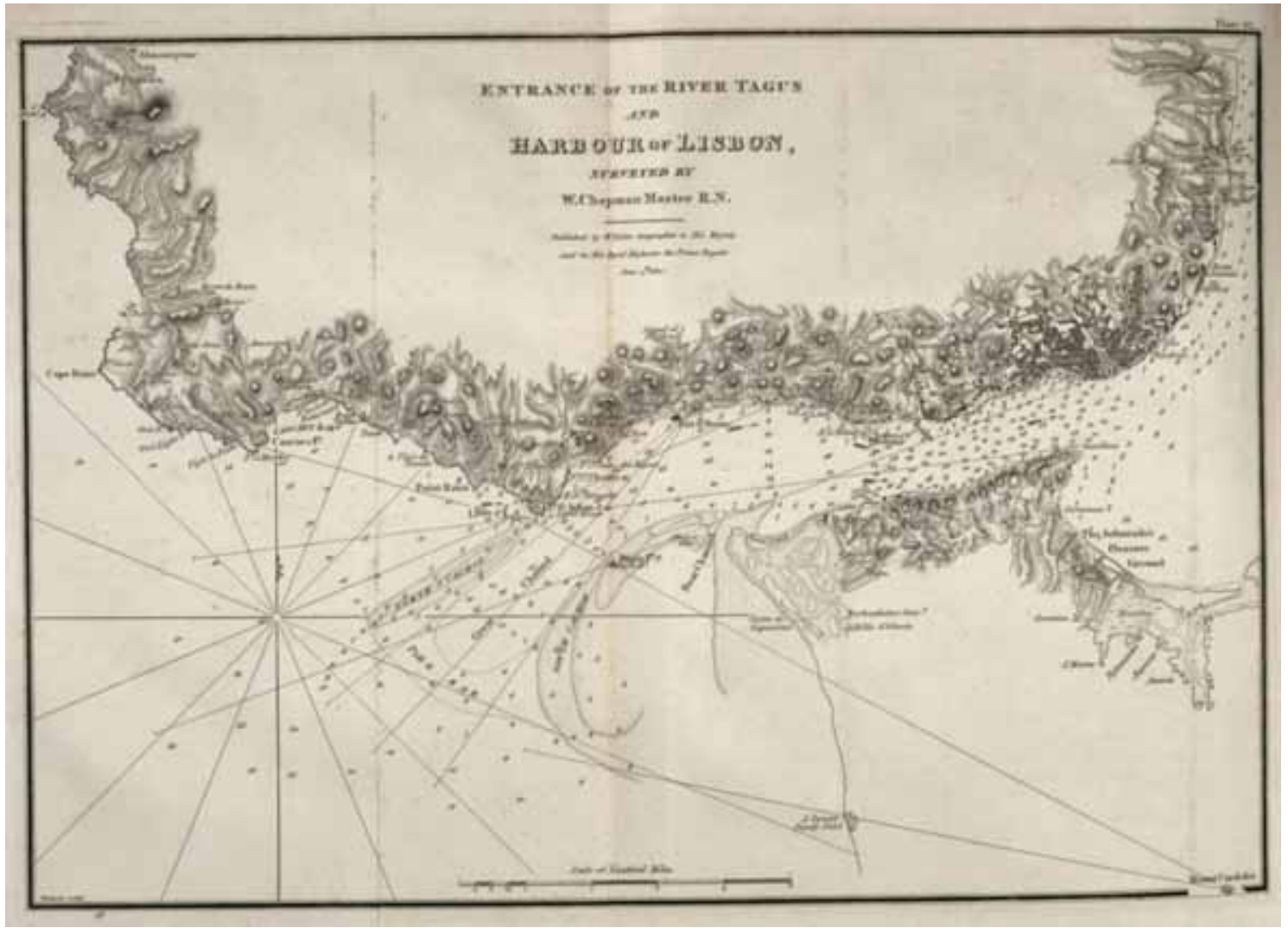

Entrance of the River Tagus and Harbour of Lisbon [1812 ?] / Surveyed by W. Chapman Master R. N. Museo Naval. Signatura: MN_A_10022_18 (Biblioteca virtual del patrimonio bibliográfico)

Queda por señalar, a título de curiosidad, recogida por varios investigadores portugueses, que las primeras referencias relativas al telégrafo Chappe habrían Ilegado hasta Portugal por mediación de soldados que habían participado en la campaña del Rosellón, entre 1793 et 1795 . Nada lo impide, pero el hecho de que la ligne du Midi (Línea del Mediodía) no alcanzará Montpellier hasta 1832, invita a pensar que los ecos también podrían haber llegado por otros conductos... Cabe también reseñar que un primitivo servicio telegráfico podría haber sido implantado por antiguos combatientes, con ocasión de la "Guerra de las Naranjas", en 1801 (Rollo, 2009: 37; Luna \& Sousa, 2008: 71).

\section{Francisco Ciera}

En 1803, la responsabilidad de la dirección de las comunicaciones Telegráficas (hasta entonces la transmisión de señales era competencia de la Marina) recayó en un civil, de ascendencia ítalo-portuguesa, el científico Francisco António Ciera (1763-1814), matemático, astrónomo, profesor de la Real Academia de Marina, quién acababa de 
concluir, en ese mismo año, un primer esbozo de los trabajos de triangulación geodésica de Portugal, emprendidos bajo su tutela en 1800, e interrumpidos en 1804.

Aparentemente, la incorporación de Ciera obedecía más a su reputación científica y al interés del Regente (el futuro rey D. João VI), atraído personalmente por la telegrafía óptica, que a sus conocimientos específicos en la materia.

Ello no obstante, aquél mismo año 1803, Ciera publica un "Regimento de signaes para os anuncios das circunstancias mais notáveis da navegação dos navios que se avistão do Cabo da Roca e dos que entrão ou sahem do porto de Lisboa (Luna \& Sousa, 2008: 76).

En 1804, veía la luz un nuevo Reglamento, ${ }^{4}$ editado por la Imprenta Real, pero cuya paternidad permanece en la sombra (Rollo, 2009: 37; Pedroso de Lima, 2009: 61; Pedroso de Lima, 2010: 11; Luna \& Sousa, 2008: 76).

La explicación suministrada en la página III del texto de 1804 (Pedroso de Lima, 2010, 11), permite saber que había dos tipos de señales: I. de Correspondencia, para anunciar las embarcaciones avistadas desde el Cabo de Roca, así como las "circunstancias de navegación" más importantes; II. Permanentes, emitidas desde el Castillo de San Jorge e "izadas durante un tiempo suficiente para garantizar la notoriedad de las informaciones obtenidas por mediación de varias de las primeras [señales] y reunidas en una sola [señal] de las segundas". Queda por añadir a este respecto que el código (cuando menos las señales "permanents") estaba al alcance de cualquiera, gracias a las copias manuscritas que circulaban. Un aviso publicado en el Diario oficial portugués el 24 de agosto de 1804 (Soares, 568), por el que se anunciaba la publicación del código de 1804, cuya utilización se había iniciado el 1o de enero, advertía de la introducción, en el transcurso de la impresión, de numerosas modificaciones, referidas tanto a los barcos mercantes como a los navíos de guerra, respecto del contenido de las copias manuscritas reproducidas hasta entonces y que, por consiguiente, estas dejarían de estar vigentes a partir del mes de septiembre, una vez que el telégrafo del Castillo de San Jorge hubiera izado durante todo un día la señal [5] para indicar que los anuncios se transmitían conforme al nuevo código impreso (y puesto a la venta, hemos de añadir...). En otras palabras, el telégrafo de la Linha da Barra tenía una vertiente de información pública sobre asuntos relativos al tráfico marítimo y fluvial.

Este mismo código de 1804 establecía el empleo, para la transmisión de las "señales de correspondencia", de 10 banderas, un gallardete y un balón, y sus combinaciones.

4 Regimento de signaes para os telegraphos da marinha/feito por ordem de S.A.R. Principe Regente N.S. 
Sea como fuere, no parece ofrecer dudas que la misión atribuida a Ciera se situaba más allá de la línea de semáforos y señales heredados de la tradición naval, y que su objetivo consistía en mejorar las prestaciones de la comunicación a todos los niveles.

También en 1803, y según un documento fechado el 16 de septiembre, o sea dos meses después de una comunicación (12 de julio) que atestigua el desempeño de sus nuevas funciones (Luna \& Sousa, 2008: 76; Pedroso de Lima, 2010: 28), Ciera proporcionaba una descripción del primero de los dos sistemas de su invención: el Telégrafo de persianas (postigos, persianas o palhetas) [Fig. 2]. Las combinaciones binarias (abierto/cerrado, mediante el accionamiento de las respectivas cuerdas manipuladas por el operador) de tres tablas o persianas de madera, cuadrangulares, pintadas de rojo (Raeuber, 1993: 96), ${ }^{5}$ enmarcadas en un bastidor, también de madera, y situadas a dos niveles (una, en el centro, sobre la línea superior; dos laterales, sobre la línea inferior) permitían componer 8 posiciones (6 cifras de 1 a 6 y dos signos de servicio) que remitían a un código.

Fig. 2.

\section{Telégrafo de persianas (Telégrafo de palhetas)}

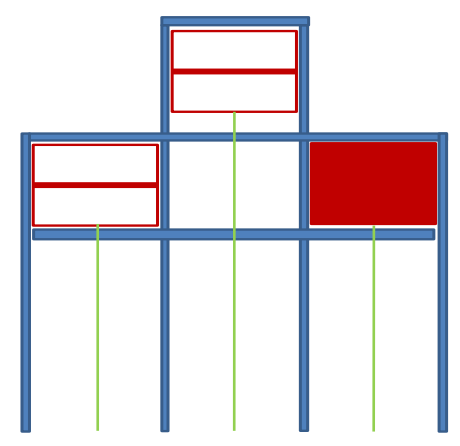

Croquis Marta Multigner

5 Una descripción mucho más tardía (reproducida a continuación por los datos que proporciona) afirma que las persianas estaban pintadas en blanco y negro: Recordamo-nos de ter, por algumas vezes, visto funccionar esse telegrapho, a cujo serviço estavam dois veteranos que se revezavam de seis em seis horas. Era muito curioso o seu serviço que demandava a maior attenção. $O$ telegraphista estava sentado n.um banco alto, para melhor poder consultar alternadamente os dois oculos de alcance que se conservavam assestados, cada um, em orificio proprio aberto na parede. Do tecto da pequena e estreita casita pendiam tres cordas, cada uma das quaes correspondia a uma das tres grades de madeira, pintadas de branco e preto, para signaes. O veterano servia-se da mão esquerda para com o auxilio das cordas imprimir movimento aos quadros e transmittir signaes; e com a direita ia escrevendo n.uma ardósia os signaes que recebia, designados por algarismos, os quaes depois passava ao papel, enviandoo ao governo civil, onde eram decifrados (Augusto de Oliveira Cardoso Fonseca, Outros Tempos ou Velharias de Coimbra. 1850 a 1880, Lisboa, Livraria Tabuense, 1911, 88-89, nota 6, en Rodrigues, M., 8889). 
Los operadores recibían las "Instrucciones para el servicio", mientras que los remitentes y destinatarios cifraban y descifraban los mensajes recurriendo a las "Tablas Telegráficas", concebidas, unas y otras, por el propio Ciera. Cabe señalar que estos textos eran manuscritos y que sólo una edición de las "Tablas", la de 1810, llegó a imprimirse, a cargo de la Imprenta Real. La estructura de las tablas impresas (90 páginas, 108 entradas -letras, palabras o frases- en la mayoría de las páginas, es decir 9720 entradas, en números redondos) y la expresión de los términos (mediante la conjunción de las cifras correspondientes a cada una de las 36 líneas y de las tres, o cuatro, columnas por página) evocan las que se adoptarán en España para la confección del Diccionario Telegráfico impreso en 1858, presumiblemente aplicado, según Sebastián Olivé (1990: 51-53), a la codificación de mensajes transmitidos por el telégrafo eléctrico.

En el transcurso de esta primera década del siglo XIX, Ciera pondría a punto otro sistema, conocido como Telégrafo de puntero (Telégrafo de ponteiro), de flecha o de aguja. Se trata ${ }^{6}$ [Fig. 3 a], en efecto, de una pieza de madera que pivota 360 alrededor de un mástil sobre el que está engastada, mediante el movimiento de una manivela accionada por el operador, que transcribe sobre una pizarra los signos observados a través del catalejo. La flecha, también pintada de rojo ${ }^{7}$, adopta 8 posiciones respecto del mástil [Fig. 3 b], el mismo número que en el caso del telégrafo de persianas. Dicho de otro modo, el puntero forma ángulos equivalentes de 45ㅇ, que corresponden, en el sentido de las agujas de un reloj, a las cifras que van de 1 a 6 , teniendo en cuenta que las posiciones $12 \mathrm{~h}$ y $6 \mathrm{~h}$ se atribuyen a dos señales de servicio. Según Ciera, estas cifras tomadas de dos en dos, tres cuatro, cinco y seis, permiten componer más de 60.000 entradas recogidas en su diccionario.

Fig. 3 a

Telégrafo de puntero (Telégrafo de Ponteiro)

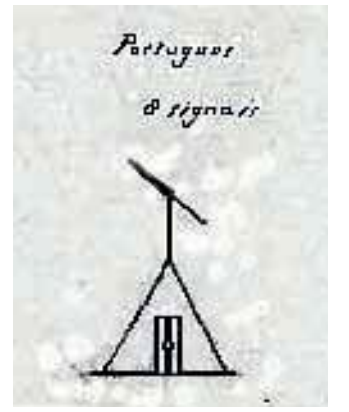

Dibujo Ciera 25.10.1808. PT AHM-DIV-1-14-170-07_m0002[1]

6 Vid. Ciera, carta del 25 de octubre de 1808, PT AHM-DIV-1-14-170-07_m0002[1].

7 Para destacar respecto del fondo azul del cielo, atendiendo a la situación de ambos colores en el espectro y a la utilización de anteojos acromáticos (Vid. Costa Dias, Comunicação...). 


\section{Fig 3 b.}

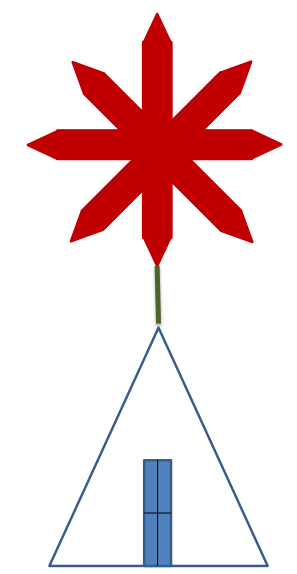

Puestos a establecer semejanzas entre los telégrafos de Ciera y otros sistemas previos, es inevitable mencionar (pese a que entre aquellos y estos hay diferencias muy apreciables) el del Almirantazgo británico o de Georges Murray (1795) comparado con el telégrafo de palhetas, o el Radiated Telegraph del reverendo John Gamble (1797) como precedente del telégrafo de ponteiro. Pero de ahí a ignorar a Ciera, su telégrafo de flecha y el papel desempeñado por este último durante la guerra peninsular, o confundirlo con Gamble, como podrá verse más adelante, media un considerable equívoco. A riesgo de buscar otras semejanzas, puede apuntarse la que cabe establecer entre el telégrafo de puntero y el de Bréguet-Betancourt (1798).

Por lo que se refiere a la fecha de implantación de esos dos sistemas, las versiones de los investigadores son un tanto contradictorias (Luna \& Sousa, 2008: 76; Pedroso de Lima, 2009: 61). Sin perjuicio de lo cual, es presumible que la del telégrafo de persianas haya precedido a la del telégrafo de puntero.

Frente a su ventaja desde el punto de vista de la instalación y de la maniobrabilidad, sobre todo en campaña, el flanco débil del telégrafo de puntero era su alcance o visibilidad: mientras que éste, según su propio autor, no debía llegar a superar las 2,5 leguas (siempre en función de las dimensiones de la flecha), ${ }^{8}$ el telégrafo de persianas permitía alcanzar entre las 3 y las 6 leguas. $^{9}$

Aunque se carece de datos precisos sobre esta cuestión, parece que la simplicidad de los sistemas de Ciera representaría una cierta desventaja respecto de otros telégrafos por lo que se refiere a la velocidad de transmisión.

8 PT AHM-DIV-1-14-170-07_m0002[1] et m0003[1]

9 Para más amplia información acerca de estos dos sistemas, véanse los autores ya citados: Luna \& Sousa, 76-77; Pedroso de Lima, 2010, 16-23; 2009, 61-65. 
También sería arriesgado pretender trazar con exactitud el estado de las líneas y de los sistemas instalados entre 1803 y finales de 1807, coincidiendo con la primera invasión napoleónica. El interés del Príncipe Regente por este medio de comunicación se plasmaría en la instalación de una red que enlazaba los reales sitios de Queluz, Salvaterra de Magos, Mafra (donde el Regente se había instalado en 1805) y Ajuda. A tenor de la ya mencionada carta de Ciera, el enlace entre Lisboa y Mafra se establecía a través de una línea que pasaba por Monsanto, Sabugo y la Tapada de Mafra. Tanto Mafra, donde se había instalado un telégrafo en la terraza del palacio, como Queluz, tenían comunicación con la torre de Belém y el Fuerte de S. Julião da Barra.

Al menos el, o los, telégrafo(s) de Mafra ${ }^{10}$, si no toda la red real, estaba bajo la responsabilidad de Pedro Folque Brun (17nn-1848) [Fig. 4]. Este jefe del ejército portugués era de origen español. Nacido en una pequeña aldea de los Pirineos catalanes, Estahis (hoy Estais), en la provincia de Lérida, llegó a Portugal con menos de veinte años e hizo una brillante carrera en el seno de las instituciones militares de este país. El 11 de mayo de 1804 había sido destinado a los Telegraphos do Reino en calidad de Ayudante del Director General ${ }^{11}$, o sea de Francisco Antonio Ciera, con quien había colaborado durante los trabajos geodésicos emprendidos anteriormente por este último. El 25 de junio de 1807, el Príncipe Regente en persona expresaba su reconocimiento y recompensaba a Pedro Folque, entonces Teniente Coronel de Ingenieros, por el hecho de haber anunciado por el telégrafo de Mafra, el 23 de diciembre de 1806, el nacimiento de su hija, la infanta Ana de Jesús María. ${ }^{12}$

10 No hay que excluir la posibilidad de que en Salvaterra y en Queluz (puesto destinado a servir de escuela de formación de futuros telegrafistas en virtud de Real Orden) se hubiera instalado más de un telégrafo (Vid. Rollo, 37 et 78 [n. 19]).

11 Vid. Hoja de Servicio, Brigadeiro Graduado Pedro Folque, Arquivo Histórico Militar (AHM).

12 http://monarquia-real.blogspot.com.es/2008/05/infanta-d-ana-de-jesus-maria-herdeira.html 


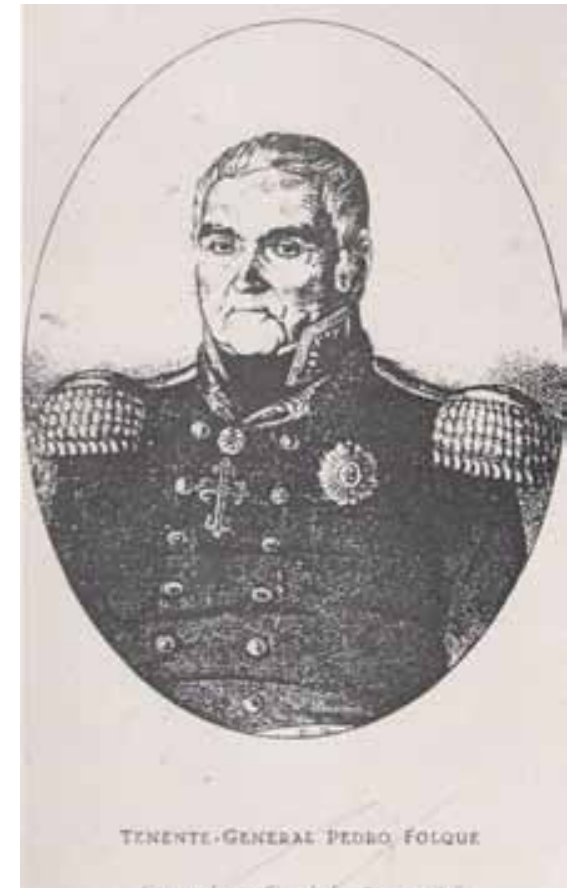

Fig. 4

En Raeuber, il. № 23 [Revista da Engenharia Militar. Número comemorativo do III Centenario da Engenharia Militar 1947]

Durante este período, las fuentes mencionan la instalación, a lo largo de la Linha da Barra, de los dos modelos de telégrafo concebidos por Ciera.

Ya funcionaban dos telégrafos de puntero, en Belém y en S. Julião, en octubre de 1808. ${ }^{13}$ Simultáneamente, con toda probabilidad, con los telégrafos de banderas allí instalados. Habría que añadir que, a partir de una fecha todavía imprecisa, durante el mandato de Ciera, sólo la Torre de Belém comunicaba con los navíos. ${ }^{14}$ Teniendo en cuenta el alcance y la manejabilidad de los telégrafos de puntero, muy superiores a los de banderas, y que la distancia entre los distintos puestos de la Linha da Barra no sobrepasaba los 3 kilómetros, la petición de Ciera del 19 de octubre de sustituir nueve de estos por cuatro de aquellos, parece estar plenamente justificada (Pedroso de Lima, 2010, 29).

Según Luna \& Sousa (78), antes de finales de octubre de $1808<<$ dos de los semáforos de la línea costera, entre Oitavos y Lisboa, ya habían sido sustituidos por los nuevos telégrafos de persianas $>$. Uno de ellos quizás era el que corona la Torre de Belém, de acuerdo con los dos testimonios gráficos que he podido recoger y que se reproducen a continuación. En el primer grabado [Fig. 5 a] se aprecia el telégrafo de persianas, pero también dos mástiles que podrían corresponder a los de los telégrafos de banderas y

13 Ciera, carta de 25.10.1808, PT AHM-DIV-1-14-170-07_m0001[1]; Pedroso de Lima, 2010, 29.

14 Vid., en relación con esta red áulica, Luna \& Sousa, 77; Pedroso de Lima, 2010, 12-13; As transmissões militares, 15. 
de puntero... En el segundo [Fig. 5 b], el telégrafo de persianas compone el signo 2 o el 4, y también se distingue claramente un mástil.

Fig. 5 a

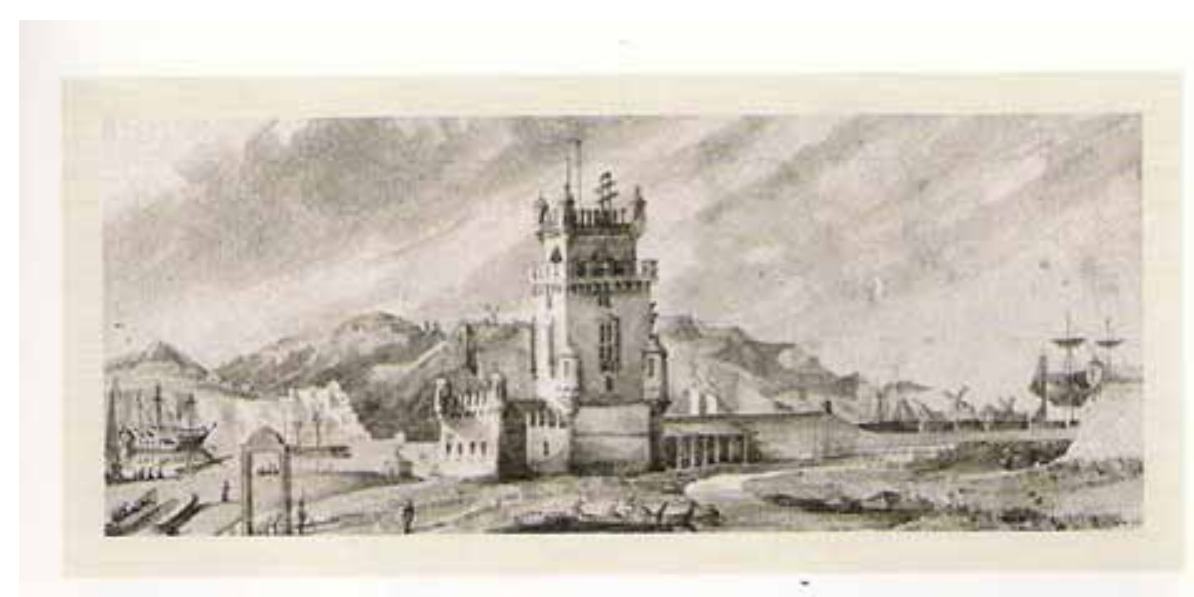

I Torre de Belém com o telégrafo de palhetas no inicio do séc. XIX

As transmissões militares, 15.

Fig. 5 b

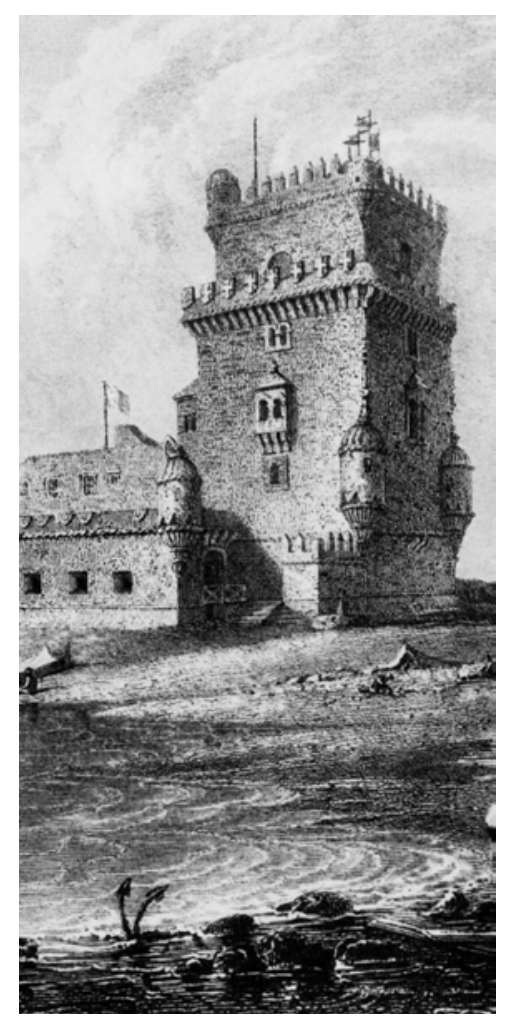

Tele-Comunicações Militares. Innovação e Soberania Nacional, Fundação Portuguesa das Comunicações, Museo das Comunicaçoes. . Exposición 19.5.2008-31.3.2009 


\section{Red regia}

Queda por confirmar el tipo de aparatos instalados en la red de las residencias reales (presumiblemente telégrafos de puntero, sin excluir por ello los de persianas) ${ }^{15}$ y la suerte que estos últimos corrieron.

Recordemos que Junot, quien se instalaría en el palacio de Queluz, había entrado en Lisboa el 30 de noviembre de $1807^{16}$ y que la familia real había embarcado la víspera para Brasil. A comienzos de mes, el Príncipe Regente había dispuesto "el establecimiento de telégrafos en las márgenes del Tajo y costas adyacentes" (Luna \& Sousa, 2008: 77). En la Orden se habla del suministro de las "barracas" (término aplicado a las tiendas o cabañas cónicas que daban cobijo a los operadores y a los instrumentos de transmisión de los telégrafos de puntero) necesarias. No obstante, en su carta del 25 de octubre, Ciera manifestaba que, además de los 11 telégrafos construidos por el capitán Matheus, dos de los cuales, como hemos visto, estaban instalados en Belém y en S. Julião, y los restantes almacenados, se habían encargado al Arsenal del Ejército otros 7, cuya construcción "no había podido concluir a consecuencia de la marcha de S.A.R.". De ahí que no parece arriesgado afirmar la presencia de telégrafos de puntero en la red regia.

Raeuber (1993: 96), por su parte, al referirse a los "enlaces o redes de comunicación telegráfica operativos de forma permanente o durante breves períodos" a lo largo de la campaña de 1810-1811, afirma que El aparato de transmisión [instalado en la Linha da Barra, entre Oitavos y Lisboa] "era un telégrafo óptico del tipo 'de persianas".

El próximo capítulo, que se corresponde cronológicamente con la segunda y con la tercera invasión napoleónica de Portugal, abordará la presencia del telégrafo durante las guerras peninsulares. Antes de adentrarnos en este apartado, no estaría de más, a riesgo de adelantar algunas conclusiones, aportar algunas precisiones relativas a los ejércitos imperials.

\section{Las comunicaciones en el ejército imperial}

15 As transmissões militares, 15.

16 La derrota de Vimeiro del 21 de agosto de 1808, a la que siguieron la capitulación de las tropas imperiales y el Convenio de Sintra, marca el fin de la primera invasión napoleónica. 
Con objeto de reproducir textualmente las opiniones de algunos autores que se han ocupado del tema de las transmisiones,

Napoleón preocupado por la eficacia de su estrategia, siempre prestó gran interés al desarrollo de las comunicaciones telegráficas, sin depositar, no obstante, una confianza absoluta y definitiva en este sistema que podía fallarle bruscamente. Razón por la que Órdenes verbales, redobles de tambores, toques de trompetas, envíos de estafetas, tales eran pues los grandes medios de telecomunicaciones del Gran Ejército. (Rolland \& Quennevat).

En este mismo sentido, Raeuber (95) subraya que

Francia no disponía en aquél entonces de una red muy extensa de telégrafo del tipo Chappe que sin embargo no se implantó en la Península ibérica. En efecto, el ejército francés de Portugal sólo utilizó fuegos de alarma, y ello cuando se encontraba en posiciones más o menos estacionarias, como ocurrió durante los asedios de Ciudad Rodrigo o de Almeida y, más tarde, ante las líneas de Torres Vedras, así como en la posición de Santarém. Sólo hay unas pocas referencias a este sistema.

¿A qué se debe entonces esta afirmación del poeta e historiador británico Robert Southey?:

The French had some small garrisons upon the coast, about twenty miles off, in the little fort of Nazareth [Nazaré], S. Giam [São Gião] and S. Martinho, which communicated with each other by telegraphs, and drew rations every day from the adjoining country. The Juiz of Pederneira was compelled to furnish these; in this time of alarm he was called upon to store them with a convenient stock beforehand and because this was not, and could not be done in a few hours, they began to pillage the neighbourhood. Provoked at this, the fishermen fell upon a Frenchman, who was going with dispatches from S. Martinho to Nazareth and murdered him, crying, Down with the French! The Sentinel at the Signal-post had the same fate.. the signal-post was broken and the country round about was presently in insurrection. (1823: 491)

Los acontecimientos descritos se producían en julio de 1808. Luna \& Sousa (2008: 78), de quienes procede la referencia, plantean la hipótesis más verosímil, en el sentido de que los fuertes costeros en cuestión, entonces ocupados por las tropas napoleónicas, podían disponer efectivamente de semáforos navales, instalados con anterioridad por los portugueses. 
Por lo que se refiere a España, convendría señalar que, al margen de una expresión gráfica, más propia de la ficción que del anacronismo, observada por Olivé (27), ${ }^{17}$ no hay ninguna huella telegráfica en el seno de las campañas y ocupación imperiales.

\section{La red nacional Ciera/Folque}

Mientras Napoleón no experimentaba la necesidad de comunicaciones telegráficas en el marco de la estrategia de sus campañas, tanto Francisco António Ciera y el ejército portugués, por un lado, como el futuro duque de Wellington, por otro, apostaban por este medio de comunicación. En el bien entendido de que las circunstancias de una iniciativa ofensiva e invasora no son las mismas que las de un planteamiento defensivo.

Así las cosas, en diciembre de 1808, con el fin de reforzar la defensa y la seguridad nacional $y$, en la medida de lo posible, la independencia del país, Ciera presenta un presupuesto de red, a implantar en un plazo de seis meses. Red que comprendía una línea que iba desde Monsanto [estación que empalmaba, vía Castillo de San Jorge, con la Linha da Barra (31 kms) que, en aquella época, según Raeuber (98), no llegaba más allá de Oitavos/Cabo Raso, y que, por tanto, se convertía en el eje de la telegrafía óptica en Portugal] hasta Almeida (305,5 kms). A la altura de Santarém, la línea entroncaba con una primera ramificación que llegaba hasta Elvas (130 kms), en la frontera española con Badajoz, en Extremadura. Una segunda ramificación, un poco más al Norte, partía de Atalaya hasta Abrantes (21 Kms). En total, 24 nuevas estaciones, es decir sin contar las cuatro supervivientes de la Linha da Barra, para apenas $500 \mathrm{kms}$ de líneas (487,5 kms exactamente), atendidas por voluntarios entre los oficiales subalternos y militares inválidos o en la reserva (Luna \& Sousa, 78). Esto representaba, incluidos los operadores de la Linha da Barra, una plantilla de 82 personas (Raeuber, 1993: 98-99). Lo que suponía un promedio de 3 personas por estación, y una distancia media de 17,4 kms entre estaciones, que iba de los 7,5 kms entre la Torre de Belém y el Castillo de San Jorge, hasta los 40 kms entre Almeirim y Montargil, en la línea de Elvas.

Los trabajos, bajo la dirección de Pedro Folque, arrancaban a comienzos de 1809. La línea de Abrantes ya funcionaba en el mes de noviembre. Y las de Almeida y Elvas lo hacían, presumiblemente, desde enero/febrero de 1810 (Rollo, 2009: 38 y 79 [n. 33]; Pedroso de Lima, 2010: 15; Luna \& Sousa, 2008: 79 [n.39]). En cambio, según Raeuber, "a 12 de abril de 1810, la línea de Almeida sólo era operativa hasta Carvalhedas" (1993: 98) mientras que la de Elvas no lo sería hasta 1812 (1993: 99), lo que parece

17 El libro de este especialista reproduce un fragmento de una imagen de Épinal (Entrée de Napoléon à Madrid), litografía de Pellerin, fechada en 1877, en la que, en primer plano, se ve a Napoleón a caballo, y al fondo, sobre la torre de una iglesia, un telégrafo Chappe... 
improbable. También según Raeuber (99 y 103), los aparatos utilizados son objeto de hipótesis. No obstante, el historiador suizo, aun admitiendo la existencia de "otro aparato portugués", se inclina por los telégrafos de persianas, en razón de las distancias "a veces enormes entre las estaciones de relevo", lo que, según él, exigiría "persianas mucho más grandes que las utilizadas en la línea Oitavos-Lisboa", aspecto sobre el que volveré con ocasión de las líneas de Torres Vedras. En cuanto a los anteojos, algunos documentos permiten confirmar su importación de Inglaterra.

El siguiente croquis reproduce la red del "telégrafo portugués" [Fig. 6], a la que Raeuber llama de buen grado "Red Folque", en funcionamiento ya desde febrero de 1810 (con las reservas expresadas más arriba).

Fig. 6

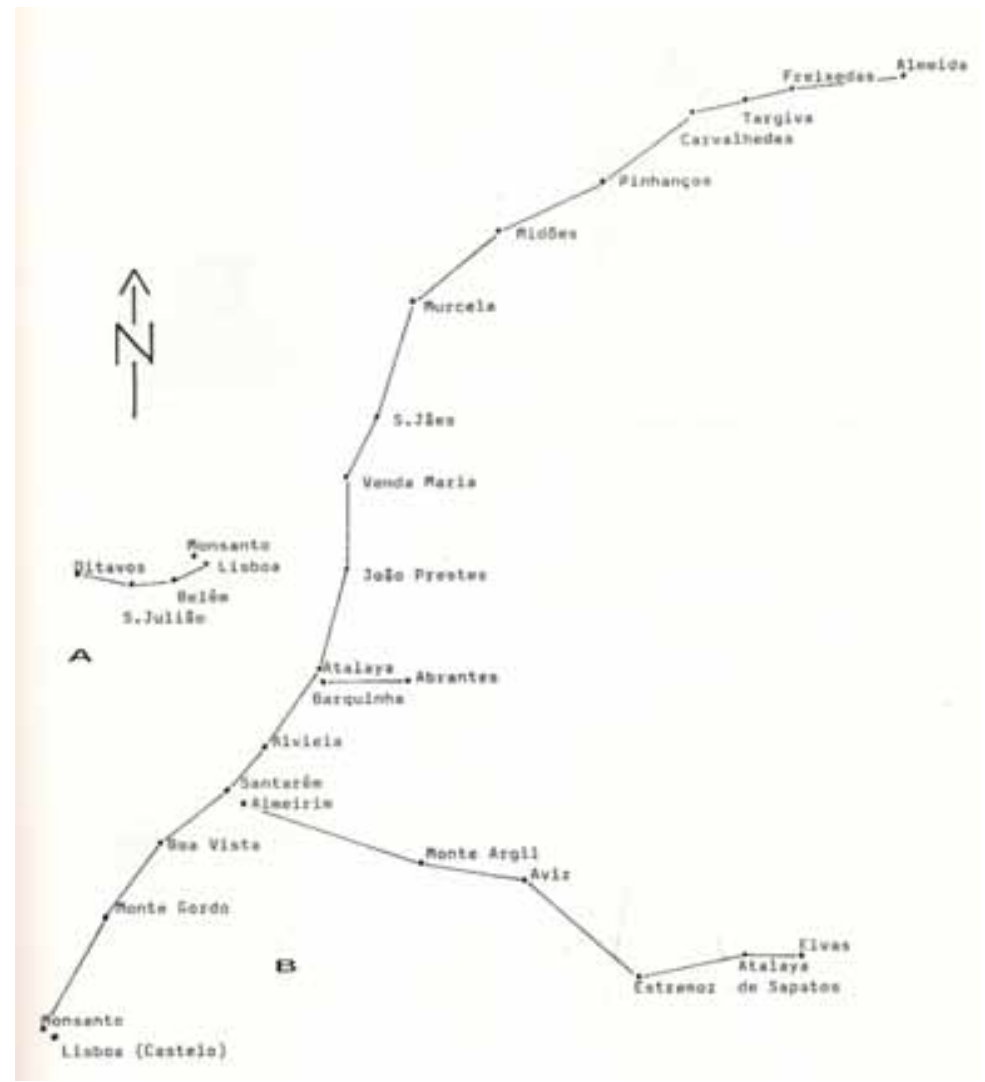


La función crea el órgano. De tal forma que, por Decreto de 5 de marzo de $1810,{ }^{18}$ nacía, dependiendo del ministerio de la Guerra, el Corpo Telegráfico, el Cuerpo telegráfico, situado bajo la dirección de un civil, o sea de Francisco António Ciera, y de su adjunto, João Leal Garcia, entonces Sargento Mayor de milicias, quien, más adelante, sustituiría a Ciera, fallecido en 1814, al frente del Cuerpo. Con fecha 13 de mayo de 1810, la red se dividía en tres distritos cuya responsabilidad recaía en los oficiales de Ingenieros Pedro Folque, Francisco Blank y José Freire.

\section{La defensa de Lisboa}

Arthur Wellesley tenía ideas muy arraigadas sobre las prioridades estratégicas en Portugal. El 20 de octubre de 1809, es decir una vez rechazada la segunda invasión del país por las tropas de Napoleón, en su informe dirigido al teniente coronel Fletcher, comandante del Real Cuerpo de Ingenieros, desde Lisboa, donde había desembarcado el 2 de abril, el vizconde de Wellington afirmaba: "The great object in Portugal is the possession of Lisbon and the Tagus, and all our measures must be directed to this object". Tras haber expuesto las distintas posibilidades de ataque y defensa, en función de las circunstancias y de las estaciones, y de haber destacado la importancia de Torres Vedras, le transmitía 21 instrucciones a Fletcher para estudiar el terreno, adoptar determinadas medidas y emprender diferentes trabajos de construcción y de fortalecimiento. Entre estas consignas, la 18, cuyo tenor era el siguiente: "He [Fletcher] will fix upon spots on which signal posts can be erected upon these hills, to communicate from one part of the position to the other" (Dispatches [Services], 1836, Vol. V, 230 et 235). En otras palabras, Wellington adoptaba sus primeras disposiciones relativas a la defensa de la capital, incluidas las que permitían garantizar las comunicaciones.

Las tareas de fortificación empezaron a finales de 1809. A grandes rasgos, los británicos construyeron cinco líneas de defensa para proteger Lisboa. Las dos primeras, las más conocidas, las de Torres Vedras, a $30 / 40 \mathrm{kms}$ al Norte de la ciudad, de 46 y $40 \mathrm{kms}$ de longitud, respectivamente, y a $13 \mathrm{kms}$ de distancia una de otra, se extendían desde el Tajo hasta el Atlántico. La tercera línea, cuya única finalidad era la de proteger, en su caso, el reembarque de las tropas inglesas, de unos 3 kms de largo, rodeaba la bahía del Fuerte de São Julião da Barra, desde Paço de Arcos hasta Carcavelos. Las dos últimas estaban situadas en la margen izquierda del Tajo para prevenir una eventual incursión enemiga desde el Alentejo; la cuarta, entre Costa de Caparica y Almada, compuesta por 17 reductos a lo largo de 7,5 kms; y la quinta, dotada de 7 reductos, en las elevaciones al Norte de Setubal.

18 Disposición respaldada por un documento firmado por el ministro de Asuntos Exteriores y de la Guerra, Miguel Pereira Forjaz, y que llevaba por título: Organizaçao e Regulamento de disciplina do Corpo destinado ao Serviço dos Telégrafos, com aprovação de SAR o Principe Regente. 
Las líneas estaban constituidas por 152 fortalezas y reductos. Las 126 que pertenecían al sistema defensivo de Torres Vedras, de las que se conserva un gran número, construidas en un plazo digno de mención (entre noviembre de 1809 y septiembre de 1810), ya estaban terminadas a la llegada de Masséna. La construcción del resto se escalonará hasta 1812. El mapa reproducido a continuación [Fig. 7] recoge las tres primeras líneas y permite situar el emplazamiento de las dos últimas.

\section{La tercera invasión y los telégrafos de Wellington}

En los relatos de los expertos António Ventura, Alexandre de Sousa Pinto y Antonio Pedro Vicente, incluidos en la obra coordinada por Miguel Corrêa (As linhas de Torres Vedras), el lector encontrará una amplia y precisa descripción histórica, bellamente ilustrada, de este decisivo episodio de la guerra peninsular, que señalará el comienzo del fin de la última invasión napoleónica de Portugal.

Fig. 7

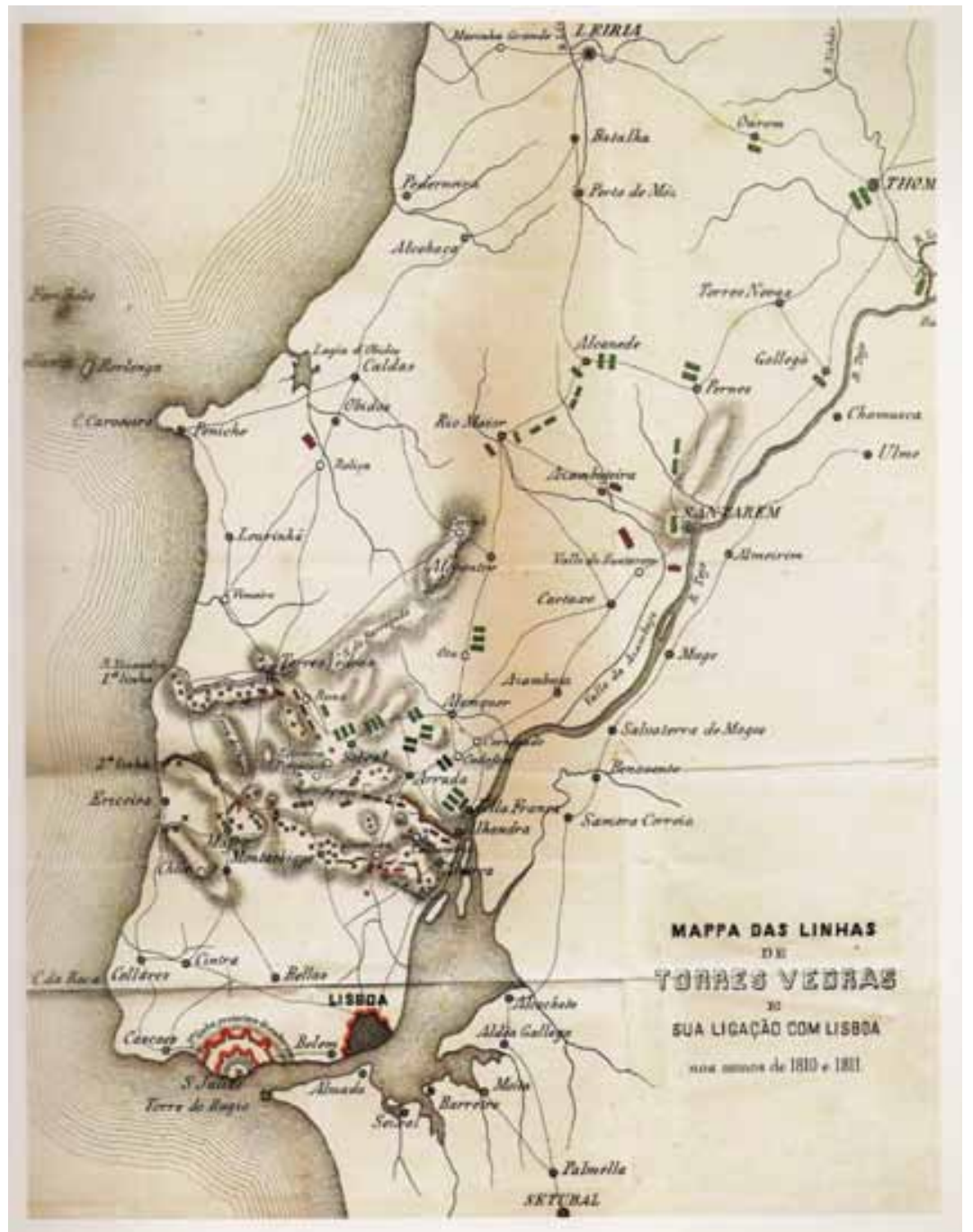


La investigación histórica emprendida por Isabel de Luna y Ana Catarina Sousa, con la colaboración de Rui Sá Leal (Telegrafia visual na guerra peninsular.1807-1814) representa, por otra parte, el análisis más exhaustivo de la red de telegrafía óptica implantada en Portugal durante la campaña 1810-1811 por Wellington, red que, con toda justicia, podría llevar el nombre de este último, sin olvidar por ello la estrecha colaboración de Ciera y del Corpo telegráfico portugués.

El comandante supremo de las fuerzas británicas en la península ibérica tenía conocimiento del sistema semafórico de la Navy (flags and pendants/pennants, banderas y gallardetes) así como del código utilizado, obra del almirante Home Popham. El vicealmirante Berkeley y el teniente coronel Fletcher eran depositarios de su confianza, pese a las discrepancias que le enfrentaban al primero. La copiosa correspondencia de guerra de Wellington ${ }^{19}$ proporciona informaciones apreciables sobre el telégrafo, ámbito en el que se proponía desempeñar un papel influyente.

Ya desde el 15 de junio de 1810, reclamaba, desde Celorico da Beira, la colaboración de Berkeley para la implantación del servicio telegráfico. Poco tiempo después, en un despacho fechado el 24, también dirigido a Berkeley, quien le había contestado el 20, le da abundantes precisiones y plantea diversas preguntas sobre la estructura del telégrafo (mástil, verga -Berkeley era partidario de una verga atravesada en el centro por el mástil, mientras que Wellington prefería, como así ocurrió, que sólo tuviera un brazo, para facilitar la lectura-, travesaño...), el número de estaciones y de operadores, etc., acompañadas de un croquis que se reproduce a continuación [Fig. 8]. En un mensaje dirigido a Charles Stuart, unos días antes, el 20, no tenía reparos en decirle que el código Popham le parecía very intricate and very imperfect, opinión compartida por Beresford (Dispatches, 1836, Vol. VI, 188, 215-216 y 207).

Fig. 8. Telégrafo propuesto por Wellington

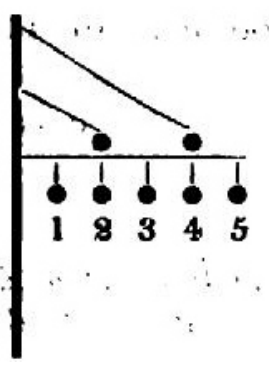

Dispatches, 1836, vol. VI, 216

19 Recogida especialmente en Dispatches y Supplementary Despatches. 
En su informe, muy minucioso, del 8 de junio de 1810 (Supplementary Despatches, 1840, Vol. VI, 546-547), Fletcher proporciona una descripción bastante detallada del telégrafo de las líneas de Torres Vedras en los siguientes términos:

This telegraph consists only of five balls, a flag and pendant, of any colour; and if more than one thousand signals are requisite, then an additional flag and pendant. It might be executed, with four balls, but the combination would require sometime three balls to be hoisted; whereas, by having five balls, no more than two are ever hoisted on the same combined line. The drop balls, which are only two in number, ought to have distance-lines fixed to them, not only for ascertaining their position, but likewise to hook to the bottom of the upper ball when a combination of the sort is wanted.

Descripción a la que siguen varios croquis muy ilustrativos [Fig. 9], reproducidos a continuación:

Fig. 9

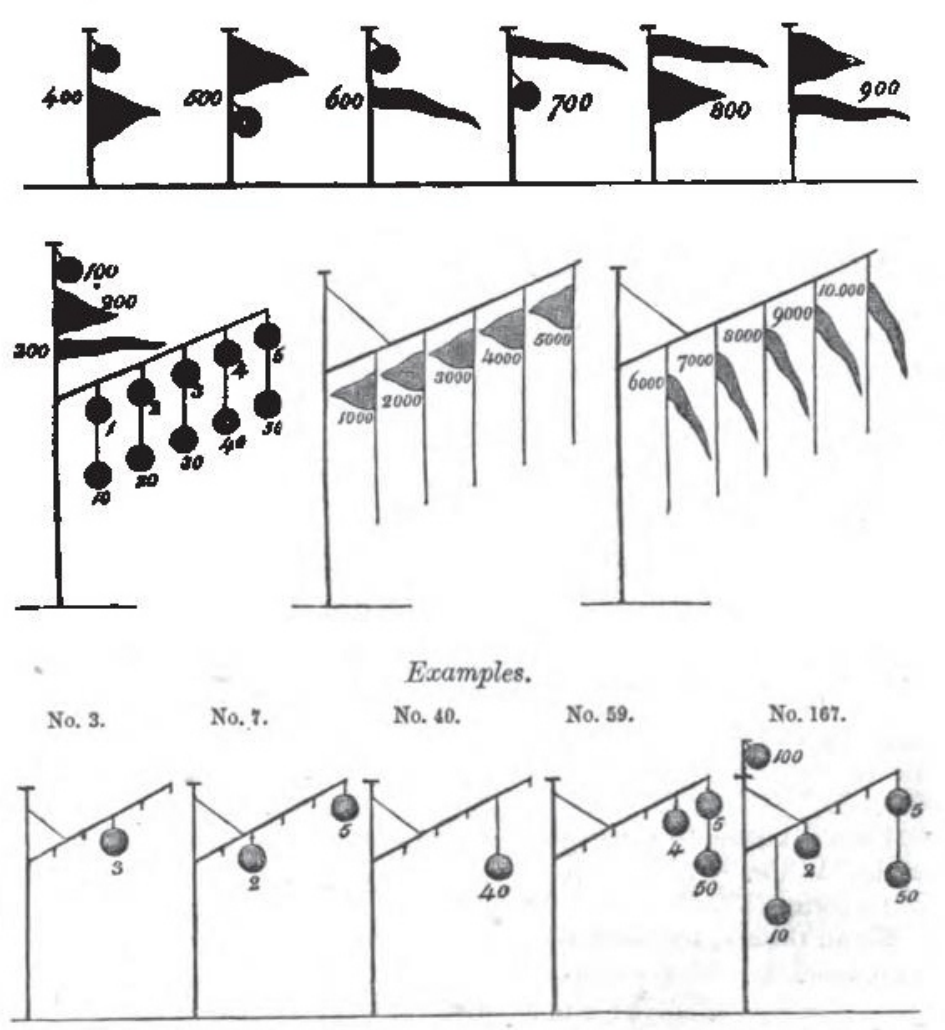

Supplementary Despatches, 1840, vol. VI, 547

Dicho de otro modo, se trataba de combinar 1 o 2 banderas, 1 o 2 gallardetes y un máximo de 5 balones, izados en el mástil [Fig. 10], por encima y/o por debajo de la verga, mediante cinco drizas verticales y paralelas, para componer líneas de cifras que 
remitían a un código e iban del 1 al 9: centenas (balón, bandera, gallardete), unidades de millar (bandera, gallardete), unidades y decenas (balón). ${ }^{20}$ Estaba previsto un mecanismo para, en su caso, enganchar, a la distancia adecuada, dos balones sobre la misma driza. Mientras que el color de las banderas y los gallardetes carecía de importancia, los balones, presumiblemente, eran negros. Luna y Sousa (98) estiman que la altura del mástil era del orden de los 10 a 12 metros. Según el capitán John Thomas Jones (105), estos telégrafos, manejados por los hombres (oficiales y marineros) de la Navy, podían comunicarse sin dificultad a una distancia de 7 u 8 millas (11 a $13 \mathrm{kms}$ ).

En suma, el telégrafo instalado en las dos líneas de Torres Vedras era una adaptación del sistema propuesto por Berkeley a las necesidades de la guerra en tierra firme, conforme a las recomendaciones de Wellington.

\section{La red telegráfica de las líneas de Torres Vedras}

Según las distintas fuentes y atendiendo al cuadro diseñado por Luna \& Sousa (2008: 92), la red de Torres Vedras estaba constituida por 10 estaciones telegráficas instaladas en las fortalezas y emplazamientos siguientes (los guarismos que preceden a la fortaleza corresponden a la numeración atribuida en los planos de los trabajos emprendidos):

1ạ línea de Torres Vedras

- $\quad 30 .-$ Forte de Grilo

- 20.- Forte de S. Vicente

- Centrale Nossa Senhora do Socorro (Serra)

- 14.- Forte do Alqueidão

- 118.- Forte dos Sinais/Moinho Branco
Torres Vedras

Torres Vedras

Mafra/Torres Vedras

Sobral do Monte Agraço

Vila Franca de Xira

\section{2a línea de Torres Vedras}

- 91.- Forte de Alagoa

- 97.- Forte de S. Julião

- 80.- Forte da Serra de Chipre

- 76.- Forte do Sonível

- Cabeço de Montachique
Mafra

Mafra

Mafra

Mafra

Mafra

20 Véase también Pedroso de Lima, 2010, 51-53. 
Fig. 10

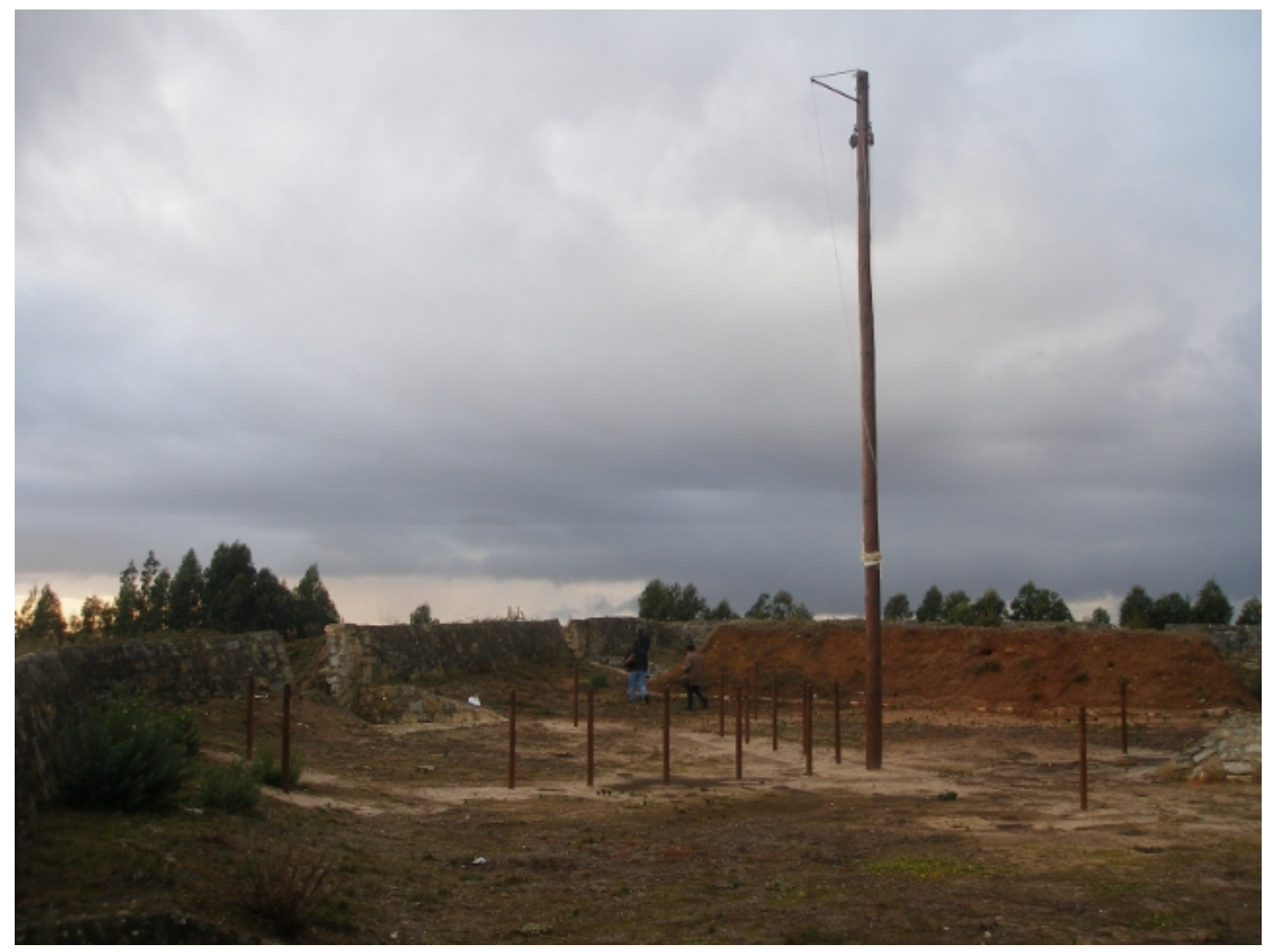

Mástil y estacas (recreación) para atar las drizas del telégrafo de balones en el Fuerte de S. Vicente

La existencia de otras estaciones (tales como las de Picanceira y Marvão) parece estar confirmada, sin que pueda precisarse su emplazamiento. En una carta dirigida a Fletcher el 3 de agosto de 1810, Jones (164) le confirma haber transmitido un mensaje (que parece ser un ensayo de comunicación) entre Alhandra y Mafra y que con un tiempo aceptablemente claro la respuesta ya no debe plantear más inquietudes.

\section{El telégrafo en Beira Alta}

A raíz de la caída de Ciudad Rodrigo, y ante el inminente regreso de las tropas napoleónicas a Portugal, lo cual acontecería el 24 de julio de 1810, Wellington tenía prisa por reforzar las defensas de los alrededores de Guarda y establecer un sistema de comunicaciones en la región (Raeuber, 1993: 99-103; Luna \& Sousa, 2009: 103-106). De hecho, desde comienzos de julio, el teniente coronel Fletcher estaba dedicado a la instalación de una red telegráfica que terminaría por enlazar (finales de julio-principios de septiembre) Guarda, Celorico da Beira (sede del cuartel general de Wellington donde la instalación del telégrafo había concluido el 12 de agosto), Maçal do Chão, Alverca, Freixedas y Almeida. Las estaciones de esta efímera línea padecerían numerosas vicisitudes como consecuencia de la capitulación de Almeida y otros episodios de guerra. En octubre de 1810 (Luna \& Sousa, 2009: 104), más al Sur, se habrían construido otras dos estaciones, en Castelo Branco y en Sarzedas. 
El modelo de telégrafo escogido era el que había sido propuesto al principio por Berkeley, es decir, una verga atravesada al centro por el mástil que la sostiene, pero, en este caso, basculante, de forma que podía adoptar tres posiciones: horizontal, inclinada a izquierda y a derecha; 4 balones negros que podían ser utilizados simultáneamente para componer las 24 letras del alfabeto inglés y un quinto balón, en lo alto del mástil, para la representación de las cifras. El código utilizado era el de Popham; pero entre las estaciones de Freixedas y Almeida se utilizaba un código suplementario de 24 cifras (el mismo número que el de letras del alfabeto) que se correspondían con otras tantas frases preestablecidas (Luna \& Sousa, 2009: 104-105).

\section{El telégrafo portugués, y sus interpretaciones, en Torres Vedras}

Los dos sistemas esbozados anteriormente no agotan la telegrafía óptica durante las campañas de la Beira Alta y de Torres Vedras. Ha llegado el momento de volver a ese "otro aparato portugués" evocado más arriba.

La línea Lisboa-Almeida, de Ciera/Folque, construida aparentemente sin que Wellington hubiese sido advertido (Raeuber, 1993: 99-100), pasaba por Carvalheda, Targiva et Freixedas, lugares próximos de Celorico da Beira. Aquí es donde Wellington habría tenido conocimiento del telégrafo portugués, cuya facilidad de manejo tenía en considerable aprecio. Hasta tal punto que, en una carta remitida desde Celorico al teniente general Stapleton Cotton, el 20 de agosto de 1810, le pedía que transmitiera a William Cox, gobernador de la plaza fuerte de Almeida, la siguiente comunicación:

Lord W. Finds the Portuguese Telegraph so convenient, that he recommends you to prepare one of the upright ones, to be put up, and used occasionally when that now in use shall be knocked down. Let the upright be as high as the present telegraph, and the board attached to the moveable beam be three feet English square, and we shall be able to distinguish it. The mode of using this telegraph is described in the Portuguese book. Have two or three of them made, in case the enemy should destroy one of them by his fire. (Dispatches, 1836, vol. VI, 348).

Este texto es especialmente interesante porque aporta la respuesta a varios interrogantes. En primer lugar, explica la presencia del telégrafo portugués en las líneas de defensa instaladas por los británicos. Luego, concreta el papel que desempeñaba: el de refuerzo o salvaguardia de los sistemas de Pennants and balls. Finalmente, informa sobre el tipo de aparato. No parece que queden dudas de que se trata del telégrafo de puntero. Y por tanto, éste era el que se empleaba en la línea Lisboa-Almeida (lo que no excluye, sin embargo, la utilización de telégrafos de persianas en esta línea...).

La cuestión se plantea respecto de las tablas de 3 pies cuadrados ingleses $\left(0,2787 \mathrm{~m}^{2}\right)$, atadas al puntero. ¿Se trata de alguna innovación sugerida por Wellington o alguien de su entorno para aumentar la visibilidad? Muy probablemente. Porque, por un lado, 
este añadido no figura en la descripción ni en el croquis de Ciera. Y por otro, pese a las afirmaciones de ciertos historiadores anglosajones ${ }^{21}$ en este sentido, no parece que el Radiated Telegraph del reverendo John Gamble haya hecho acto de presencia en Portugal. Más bien parece que, partiendo de la, antes mencionada, recomendación de Wellington, Raeuber sustenta una hipótesis o, más bien, retoma por su cuenta esta descripción para proponer una interpretación, mediante un croquis, en el que el mecanismo de manivela se sustituye, aparentemente, por una polea en la que se desliza una cuerda. Más allá de esta interpretación, nada hay para sostener la utilización, ni siquiera la existencia real de tal artefacto. De igual modo, la noción de telégrafo "portátil", "móvil" o "volante" que se pretende aplicar al telégrafo de puntero, sigue siendo bastante, incluso muy, confusa. ¿Quería señalarse quizás la ligereza de su estructura y su fácil instalación? Añadamos, finalmente, que Raeuber (1993: 103 y 97) aplica, erróneamente por cierto, las dimensiones indicadas por Wellington para esta hipotética tabla, a las de la persiana del telégrafo de Ciera.

Sea como fuere, cabe la posibilidad de que el telégrafo de puntero, caracterizado o no de esta manera, haya sido instalado en el triángulo de la Beira Alta (Celorico-GuardaAlmeida), y le permitiera así a Wellington estar enlazado con la red portuguesa. Según Luna \& Sousa, estos telégrafos eran manejados por soldados portugueses, y los mensajes transmitidos en su lengua y posteriormente traducidos. Raeuber cita informes de finales de 1810 que dan cuenta de la instalación de dos telégrafos "portátiles" (sin más) en Alverca y en Maçal de Chão. Según Luna \& Sousa, se trataría de telégrafos de puntero. De ser así, las informaciones proporcionadas por Raeuber (el emplazamiento en Alverca había sido localizado el 29 y el telégrafo estaba ya instalado al día siguiente "con la primera luz del día"; a pesar de que "se había desplomado inmediatamente después", había sido "reparado y reinstalado con la ayuda del capitán Bull de la Real artillería montada") confirmarían que la instalación, a cargo de las tropas británicas, no exigía mucho tiempo. Para añadir algo más de confusión sobre este asunto, en un extracto de una carta dirigida al coronel Murray por el general Cotton, este último explica que "se han llevado el telégrafo [de Maçal do Chão] y el de Guarda ha sido destrozado". Obsérvese que se habla "del" telégrafo, cuando debía de haber dos: un telégrafo de balones y un telégrafo de puntero... Luna \& Sousa añaden que el castillo de Guarda disponía "de un telégrafo de la red nacional", lo que plantea otra pregunta sin respuesta, toda vez que la línea de Almeida no pasaba por Guarda (Raeuber, 1993: 101-102; Luna \& Sousa, 2009: 106).

En septiembre de 1810, Wellington, en vista de las dificultades experimentadas para abonar las retribuciones de los marinos responsables de las estaciones de Torres Vedras, proseguía con su proyecto de instalar los telégrafos de puntero, al tiempo que

21 Tales como Ken Beauchamp (103), según el cual Wellington's commanders used a portable semaphore telegraph designed by Gamble. 
se planteaba la posibilidad de sustituir los telégrafos de balones, y no ya como mera salvaguardia. La implantación de los telégrafos portugueses que funcionaron simultáneamente con los otros (si bien eran incompatibles por los códigos) permitió enlazar con Lisboa y eventualmente con nuevas estaciones (Serra de Serves) desde Cabeço de Montachique, a través de la estación de Monsanto (Luna \& Sousa, 2009: 108).

Los telégrafos de las líneas de Torres Vedras, en relación con el resto de la red angloportuguesa, desempeñaron un papel importante en el desenlace de la guerra. Los puestos de balones fueron desmontados a raíz de la retirada del ejército de ocupación, en abril de 1811, mientras que los telégrafos portugueses continuaron prestando sus servicios hasta que las guarniciones desocuparon las líneas.

El desmantelamiento de los telégrafos de balones en Torres Vedras no implicó su desaparición. A medida que las tropas aliadas perseguían a los invasores, Wellington experimentaba la necesidad de mantener el contacto con los cuerpos de ejército y con la Navy. Así es como encargó al Corpo Telegráfico que suministrara los aparatos necesarios ${ }^{22}$ para la instalación de nuevas líneas (Línea de Abrantes hasta el Sur del Tajo) o la imbricación de nuevos puestos en las líneas preexistentes (Línea de Almeida). En una carta de fecha 1 de marzo de 1811, dirigida a Beresford, Wellington, entonces en Cartaxo, cerca de Santarém, le decía que la víspera había recibido una comunicación telegráfica desde Elvas, relativa a un ataque francés sobre Badajoz (Dispatches, vol. VII, 1837, 313), despacho que podría haberle llegado, bien a través de nuevas estaciones ad-hoc, bien a través de la línea portuguesa de Elvas que, según algunas fuentes, podría haber sido prolongada hasta la vecina ciudad española. ${ }^{23}$

\section{Un nuevo modelo de telégrafo}

Otros testimonios confirman que durante el asedio de Badajoz de 1812, y mientras avanzaba por el Norte de España (Pamplona, 1813) y el Sur de Francia (Bayona, invierno 1813-1814), Wellington no se separaba de su telégrafo de balones. Un documento conservado en la Universidad de Southhampton, concretamente un código de Popham, proporciona datos sobre el sistema utilizado por Wellington durante el asedio de la ciudad vasco-francesa. Contrariamente al que había sido utilizado en Portugal, no permitía componer números de más de tres cifras. El mecanismo consistía en una verga atravesada en el centro por el mástil que la sostenía y que, por tanto, presentaba dos brazos, sobre cada uno de los cuales se izaban balones, según las combinaciones establecidas para cada cifra, del 1 al 10. Teniendo en cuenta que "la misma disposición de los balones equivalía en uno de los brazos a las unidades, y en el

22 Que, eventualmente, funcionaban sólo con tres balones, según un testimonio de Ciera fechado el 20 de marzo de 1811 (Luna \& Sousa, 111).

23 http://badajoz1812.blogspot.com.es/2010/02/la-red-de-telegrafo-optico-entre-lisboa.html 
otro a las decenas, la distinción se establecía con la izada de una bandera en la driza de las decenas. De este modo el telégrafo podía ser leído desde ambos lados [origen y destino] de una línea continua de puestos de comunicación". Así es como Luna \& Sousa ${ }^{24}$ explican el funcionamiento de esta versión del telégrafo de balones (tres como máximo, simultáneamente) que puede ser considerada, muy acertadamente, como un aparato de campaña.

\section{El telégrafo en tiempo de guerra civil y de paz}

Una vez concluida la guerra peninsular, el interés de la línea de Almeida y de sus ramificaciones a Abrantes y Elvas decaerá considerablemente, hasta el punto de ser suprimidas, mientras que la actividad del Cuerpo telegráfico, cuya importancia también disminuirá sensiblemente, se concentrará exclusivamente en la Linha da Barra. En 1816, época en la que ésta había quedado reducida a Buenos Aires, Almada, S. Julião da Barra y Oitavos, se instalará un nuevo telégrafo en el Arsenal de Alfeite. Cinco años más tarde, el regreso del João VI a Portugal traerá consigo la instalación de un telégrafo en el Palacio de Bemposta, en Lisboa, y la reinstalación de otros tres, en el Castillo de S. Jorge, en Queluz y en Mafra, cuyo funcionamiento estaba reducido a las jornadas del soberano (Rollo, 2009: 38-39; Pedroso de Lima, 2010: 41-43). En ese mismo año $1821,{ }^{25}$ Pedro Folque, entonces Coronel de Ingenieros, será encargado de la Inspección de Telégrafos, función de nuevo cuño que desempeñará de forma intermitente hasta 1833 (Hoja de servicios, AHM).

Durante este período, el de la Revolución liberal, el telégrafo, por razones de seguridad nacional, recuperará un papel primordial que se plasmará en la construcción de la línea Lisboa (Castillo de S. Jorge)-Oporto, línea prevista en el Reglamento del Cuerpo telegráfico (entonces al servicio de los absolutistas de D. Miguel), de $1828,{ }^{26}$ cuyo autor era Pedro Folque; en la creación, por los liberales, en 1833, de un servicio de telegrafía óptica mediante balones en la misma Oporto, ciudad donde, en 1810, también se había instalado un telégrafo para comunicarse con los navíos ingleses; en el establecimiento de un sistema de telegrafía óptica en las Azores, para el ejército liberal; $y$, finalmente, en la instalación de un telégrafo de balones en la isla de Madeira, en 1836 (Luna \& Sousa, 2009: 114; Pedroso de Lima, 2010: 43-47).

En 1832 se comprueba la existencia de una red de tres líneas. La Linha da Barra, que se extendía desde el Castillo de S. Jorge hasta Mafra, y que llegaba hasta el Cabo de Roca, pasando por la margen izquierda, al Sur, del Tajo, y las residencias reales. La línea del

24 112-113. En relación con el asedio de Bayona, véase también Wilson, 187.

25 En esa época, el itinerario de la Linha da Barra era el siguiente: Arsenal de la Marina, Pragal, Torre de Belém, S. Julião, Parede, Oitavos, Cabo Raso, Cabo da Roca, Alfragide y Queluz.

26 Que confirma la utilización de telégrafos de persianas. Vid. Pedroso de Lima, 2010, 44 (n.78). 
Algarve, entre el Castillo de S. Jorge y Sagres. Y la línea de Oporto. Aparentemente, se había suprimido la línea de Elvas.

Doce años más tarde, o sea en 1846, seguían existiendo tres líneas, pero el trazado ya no era el mismo, salvo el de la Linha da Barra. La línea de Sagres había desaparecido, mientras que la de Oporto era sustituida por las Líneas del Norte que, partiendo de la capital y atravesando, entre otras localidades, Santarém, Abrantes, Castelo Branco, Coimbra y Porto, terminaban en Chaves (cerca de la frontera con la provincia española de Orense), el punto más septentrional jamás alcanzado por el telégrafo en Portugal. En cuanto a la línea de Elvas, se restablecía el nombre de Línea del Alentejo.

\section{Por quién doblan las campanas: el advenimiento del telégrafo eléctrico}

El tiempo de la telegrafía óptica tocaba a su fin. El 26 de abril de 1855, el ministro portugués de Obras Públicas y Alfred Bréguet firmaban un contrato para el establecimiento, en el plazo de un año, de una red de telegrafía eléctrica, de $632 \mathrm{kms}$, que enlazaba Lisboa con Mafra, Carregado (estación de empalme), Oporto (línea ferroviaria del Norte) y Elvas. El primer tramo (entre la estación principal de Terreiro do Paço, sede del ministerio de Obras Públicas; Palacio das Cortes, hoy de São Bento, sede de la Asamblea Nacional; el Palacio das Necessidades y Sintra) se inauguraba el 16 de septiembre de 1855 , el mismo día de la mayoría de edad de Pedro $\mathrm{V}$ y de su aclamación como rey de Portugal. Algún tiempo después, las líneas se extendían ya hasta Oporto, Santarém y Elvas. Mientras que las estaciones de telegrafía óptica se iban suprimiendo a medida que iban cayendo en desuso

La red, que seguía reservada para el servicio oficial (pese a que la ley preveía un uso "secundario para las correspondencias particulares") como antes la de la telegrafía óptica, también era administrada por el Corpo Telegráfico. No obstante, la presión ejercida por los particulares desembocará en la aprobación de un Decreto, el 23 de junio de 1857, por el que se regulaban la apertura del servicio al público y las tasas a percibir. En 1864 (Ley de 23 de junio), el Corpo Telegráfico, progresivamente emancipado de la tutela militar desde el advenimiento de la telegrafía eléctrica, se integraba definitivamente en la Dirección General de Telégrafos del Ministerio de Obras Públicas. ${ }^{27}$

27 En lo referente al final de la telegrafía óptica y la llegada de la telegrafía eléctrica, vid. Pedroso de Lima y Rollo, op. cit; Revista de Telégrafos (Madrid), no 2, 30 diciembre 1856, 16.; Leonardo, António José F., et al., "A telegrafia eléctrica nas páginas de "O Instituto", Revista da Academia de Coimbra”, en Revista Brasileira de Ensino de Física, v. 31, n. 2, 2601 (2009), 3-4; Pereira, Pedro Vaz, A telegrafia eléctrica em Portugal. Disponible en internet (2-12-2013): http://filaneiva.com/Documents/0001\%20A\%20Telegrafia\%20Electrica\%20em\%20Portugal.pdf 
Como en la mayoría de los países en los que la telegrafía óptica había echado raíces, la llegada del telégrafo eléctrico a Portugal anunciaba su desaparición, del mismo modo que anuncia la conclusión de este trabajo que espera haber alcanzado el objetivo propuesto, expresado en las siguientes y someras conclusiones:

La telegrafía óptica, o visual, en Portugal, a lo largo de la primera mitad del siglo XIX, ofrece una amplia variedad de sistemas y aplicaciones, tanto en el ámbito civil como en el militar, siendo éste el principal caldo de cultivo, en el que emergen las figuras de Francisco Ciera, Pedro Folque y Arthur Wellesley.

La telegrafía óptica representa una herramienta indispensable al servicio de la estrategia militar desplegada por Wellington, acérrimo partidario de su empleo durante la Guerra peninsular, a diferencia de lo que ocurre en los ejércitos napoleónicos que prescinden absolutamente de este instrumento en sus expediciones invasoras, tanto en Portugal como en España.

Contrariamente a lo que ocurre en España o Francia, donde se conservan muchas torres o torretas que sustentaban los mecanismos de los telégrafos (éstos también desaparecidos), y debido a la fragilidad de los materiales empleados para la construcción de las estructuras y elementos de señalización (madera, tela,...), no subsisten prácticamente vestigios, por lo que la investigación está circunscrita al ámbito documental, sin perjuicio del trabajo de campo a la que ésta puede dar, y da, origen.

En los últimos años, apenas veinte si se parte de las aportaciones pioneras de Raeuber, y apenas un lustro desde que se han implicado historiadores e investigadores portugueses, han surgido empeños y han aflorado trabajos respecto de los cuales el presente es manifiestamente deudor.

A este objeto de búsqueda le aguardan todavía días apasionantes porque dista mucho de estar agotado. Debo reseñar aquí las distintas iniciativas puestas en pie últimamente por diferentes organismos, civiles y militares, para la recuperación de la memoria histórica, tales como las actividades de la Comissão da Historia das Transmissões o las de varios municipios, que han desembocado en la edición de publicaciones, la construcción de maquetas, la recreación de los aparatos utilizados hace dos siglos, como es el caso del Fuerte de San Vicente, o la puesta en escena de transmisiones de época, in situ, como ocurre en la Serra de Socorro, así como sus derivadas turísticas, tales como la $<<$ Ruta Wellington $>>$.

Agradecimientos: 
Deseo expresar mi gratitud a la familia Ribeiro Cardoso-Neves Simão; a los coroneles Jose Gardete, Jorge Costa Dias y Francisco Soares, así como al general Antonio Pedroso de Lima (Commisão da Historia das Transmissões/Regimento de Transmissões); al Arquivo Histórico Militar (D. João Tavares); a la Fundação Portuguesa das Comunicações (Da Cecilia Gomes); a la FNARH.

El presente trabajo ha sido posible gracias a la amistad y hospitalidad de unos, a la acogida dispensada y a la información facilitada por otros, así como a los buenos oficios, colaboración y comprensión de los restantes.

\section{BIBLIOGRAFÍA Y FUENTES}

\section{Fuentes}

GACETA de Madrid. Disponible en internet (16-4-2013): [http://www.boe.es/aeboe/consultas/bases_datos/gazeta.php]

REVISTA de Telégrafos. Disponible en internet (14-6-3013): [http://archivodigital.coit.es/index.php/mod.articulos/mem.catalogos/relcategor ia.1096]

\section{Bibliografía}

AS TRANSMISSÕES Militares da Guerra Peninsular ao 25 de Abril (2008), Lisboa, Comissão Portuguesa de História Militar.

BEAUCHAMP, K. G. (2001) A History of Telegraphy; its technology and application. Londres, The Institution of Engineering and Technology, 2008.

CHARTRAND, R. \& YOUNGHUSBAND, B. (2000) The Portuguese Army of the Napoleonic Wars (2), Batley, Oxford, Osprey Publishing.

CORRÊA MONTEIRO, M. (coord.) (2011): AS LINHAS de Torres Vedras: um sistema defensivo a norte de Lisboa. Torres Vedras : PILT (Plataforma Intermunicipal para as Linhas de Torres).

COSTA DIAS, J. (s/f.), Comunicação sobre Francisco António Ciera no Bicentenário da criação do Corpo Telegráfico. 
DISPATCHES [SERVICES] of Field Marshal The Duke of Wellington, K.G. during his various campaigns in India, Denmark, Portugal, Spain, The Low Countries, and France from 1799 to 1818, The. Compiled from official and authentic documents, by Lieut. Colonel Gurwood, Londres, John Murray, 1834-1839.

EDINBURGH Encyclopaedia, The (1832), 1a edición norteamericana, vol. XVII, Filadelfia, Joseph Parker, 1832. Entrada: Telegraph.

FORO histórico de las telecomunicaciones. Disponible en internet (6-8-2013): [http://www.coit.es/foro/index.php?op=inicio\&PHPSESSID=0546d55e72642c443 47248c6d93de5bc]

JONES, John T. (1829) Memoranda relative to the Lines thrown up to cover Lisbon in 1810, Londres.

LUNA, I. \& SOUSA, A. C. (2009), en col. con Rui Sá Leal, «Telegrafia visual na guerra peninsular.1807-1814 ", en Boletim Cultural 2008, Mafra, Câmara Municipal de Mafra, p. 67-141.

MULTIGNER, Gilles \& ROMERO FRÍAS, Rafael, (2012) "Un siglo de comunicaciones telegráficas en Extremadura: 1810-1923", e-BIS, número 2 (julio-diciembre 2012), SEHCYT.

OLIVÉ ROIG, S. (1990), Historia de la telegrafía óptica en España, Madrid, Secretaría General de Comunicaciones, Ministerio de Transportes, Turismo y Comunicaciones.

ORGANIZAÇÃO e Regulamento de Disciplina do Corpo destinado ao Serviço dos Telégrafos. Lisboa: Impressão Régia, 1810.

PEDROSO DE LIMA, A. L. (2010), Bicentenario do corpo telegráfico 1810-2010, Lisboa, Comissão Portuguesa de História Militar.

PEDROSO DE LIMA, Major-General (2009), “A telegrafia [eléctrica] óptica em Portugal e a figura de Francisco Ciéra", en A Almenara, no 1, p. 60-65.

QUENNEVAT, J.-C. (1975), «Napoléon et les télécommunications», Revue du Souvenir Napoleonien, pp. 2-18. Disponible en internet (23-4-2014): [http://www.napoleon.org/FR/salle_lecture/articles/files/Napoleon_telecommu nications1.asp]

RAEUBER, Ch-A. (1993), Les renseignements, la reconnaissance et les transmissions militaires du temps de Napoléon: I'exemple de la troisième invasion du Portugal : 1810, Lisboa, Comissão Portuguesa de História Militar. 
REGIMENTO de signaes para os telegraphos da marinha/feito por ordem de S.A.R. Principe Regente N.S., Lisboa, Impressão Régia, 1804.

RODRIGUES, Mário Rui Simões, Da Estrada Romana ao Telégrafo Visual... por terras de Alvaiázere, Editora Folheto, 2007.

ROLLO, M. F. (2009), Historia das Telecomunicações em Portugal, Lisboa, Fundação Portugal Telecom e Ediçoes Tinta-da-China.

SOARES, J. P. C. (1863), Quadros navaes ou coleccão dos folhetins marítimos do patriota, Lisboa, Imprensa nacional.

SOUTHEY, R. (1823), History of the Peninsular War, Vol. I, Londres, John Murray.

SUPPLEMENT to the fourth, fifth, and sixth editions of the Encyclopaedia Britannica Vol.

VI, Edimburgo, 1824. Entrada: Telegraph

SUPPLEMENTARY Despatches, Correspondence, and Memoranda of Field Marshal Arthur [Wellesley, $1^{\text {st }}$ ] Duke of Wellington, K.G. Edited by his Son, The Duke of Wellington K.G., Vol. VI, Londres, John Murray, 1840.

WILSON, G. (1976), The Old Telegraphs, Londres, Phillimore, 1976.

\section{BLOGS}

Comissão da História das Transmissões (CHT). Disponible en internet (12-6-2013): [http://historiadastransmissoes.wordpress.com/tag/telegrafos-opticos/]

Real Monarquía. Disponible en internet (2-5-2013)[http://monarquiareal.blogspot.com.es/2008/05/infanta-d-ana-de-jesus-maria-herdeira.html]

La red de telégrafo óptico entre Lisboa y Badajoz. Disponible en internet (2-6-2013): [http://badajoz1812.blogspot.com.es/2010/02/la-red-de-telegrafo-optico-entrelisboa.html]

Líneas de Torres Vedras. Disponible en internet (2-5-2013): [http://linhasdetorres.blogspot.com/] 